\title{
Massive transfusion and coagulopathy: pathophys- iology and implications for clinical management
}

\section{[Transfusion massive et coagulopathie-: physiopathologie et implications cliniques]}

Jean-François Hardy MD FRCPC, Philippe de Moerloose MD, Charles Marc Samama MD PhD, Members of the Groupe d'Intérêt en Hémostase Périopératoire

"This article is reproduced, with permission, from a previous issue of the Journal; Can J Anesth 2004: 51; 293-310. Please see addendum."

Purpose: To review the pathophysiology of coagulopathy in massively transfused, adult and previously hemostatically competent patients in both elective surgical and trauma settings, and to recommend the most appropriate treatment strategies.

Methods: Medline was searched for articles on "massive transfusion," "transfusion," "trauma," "surgery," "coagulopathy" and "hemostatic defects." A group of experts reviewed the findings.

Principal findings: Coagulopathy will result from hemodilution, hypothermia, the use of fractionated blood products and disseminated intravascular coagulation. The clinical significance of the effects of hydroxyethyl starch solutions on hemostasis remains unclear. Maintaining a normal body temperature is a first-line, effective strategy to improve hemostasis during massive transfusion. Red cells play an important role in coagulation and hematocrits higher than $30 \%$ may be required to sustain hemostasis. In elective surgery patients, a decrease in fibrinogen concentration is observed initially while thrombocytopenia is a late occurrence. In trauma patients, tissue trauma, shock, tissue anoxia and hypothermia contribute to the development of disseminated intravascular coagulation and microvascular bleeding. The use of platelets and/or fresh frozen plasma should depend on clinical judgment as well as the results of coagulation testing and should be used mainly to treat a clinical coagulopathy.

Conclusions: Coagulopathy associated with massive transfusion remains an important clinical problem. It is an intricate, multifactorial and multicellular event. Treatment strategies include the maintenance of adequate tissue perfusion, the correction of hypothermia and anemia, and the use of hemostatic blood products to correct microvascular bleeding.
Objectif-: Revoir la physiopathologie de la coagulopathie chez les adultes transfusés massivement et auparavant compétents sur le plan hémostatique, à la fois dans le contexte d'une intervention chirurgicale réglée ou à la suite d'un traumatisme. Recommander les stratégies thérapeutiques les plus appropriées.

Méthode-: Dans Medline, nous avons cherché les articles traitant de "massive transfusion," "transfusion," "trauma," "surgery,"“coagulopathy" et "hemostatic defects." Un groupe d'experts a examiné les résultats.

Constatations principales-: La coagulopathie résulte de l'hémodilution, l'hypothermie, l'usage de produits sanguins fractionnés et la coagulation intravasculaire disséminée. La portée clinique des effets des solutions d'hydroxyéthyl-amidon sur l'hémostase n'est toujours pas claire. Le maintien d'une température corporelle normale est une stratégie de première intention efficace pour améliorer l'hémostase pendant la transfusion massive. Les globules rouges sont importants dans la coagulation et des hématocrites supérieurs à $30 \%$ pourraient être nécessaires à une hémostase adéquate. Chez les patients en chirurgie réglée, une baisse de la concentration de fibrinogène est observée précocement tandis que la thrombocytopénie est plus tardive. Chez les traumatisés, le trauma tissulaire, le choc, l'anoxie et l'hypothermie tissulaires contribuent au développement d'une coagulation intravasculaire disséminée et du saignement microvasculaire. L'utilisation de plaquettes et/ou de plasma frais congelé dépendra du jugement du clinicien ainsi que des résultats des tests de coagulation. La transfusion devra surtout viser le traitement d'une coagulopathie clinique (saignement microvasculaire).

Conclusion-: La coagulopathie associée à la transfusion massive demeure un important problème clinique. C'est un événement complexe, multifactoriel et multicellulaire. Le traitement comprend le maintien d'une perfusion tissulaire adéquate, la correction de l'hypothermie et de l'anémie et l'usage de produits sanguins hémostatiques pour corriger le saignement microvasculaire.

From the Department of Anesthesiology, Centre Hospitalier de l'Université de Montréal, ${ }^{*}$ Hôpital Notre-Dame, Montréal, Québec, Canada; the Hemostasis unit, Hôpital Universitaire de Genève,† Genève, Suisse; and the Département d'anesthésie-réanimation, Hôpital Avicenne, $\ddagger$ Bobigny, France.

Address correspondence to: Dr. Jean-François Hardy, Département d'anesthésiologie, Porte AS-1115-3, Pavillon Lachapelle, CHUM

Hôpital Notre Dame, 1560 rue Sherbrooke est, Montréal, Québec H2L 4M1, Canada. E-mail: jean-francois.hardy@umontreal.ca

Reprints will not be available from the authors.

Accepted for publication May 28, 2003.

Revision accepted January 5, 2004. 


\section{List of abbreviations}

aPTT activated partial thromboplastin time

BT bleeding time

DIC disseminated intravascular coagulation

FFP fresh frozen plasma

HES hydroxyethyl starch

MT massive transfusion

MVB microvascular bleeding

MWB modified whole blood

PRBC packed red blood cells

PT prothrombin time

$\mathrm{RBC}$ red blood cells

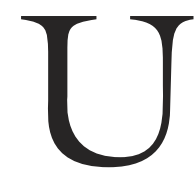

NCONTROLLED hemorrhage, and by way of consequence, massive transfusion $(\mathrm{MT})$ is a frequent complication of trauma and surgery. MT is commonly defined as the replacement of one blood mass in a period of $24 \mathrm{hr}$. A dynamic definition of MT, such as the transfusion of four or more red cell concentrates within one hour when ongoing need is foreseeable, ${ }^{1}$ or the replacement of $50 \%$ of the total blood volume within three hours, is more relevant in the acute clinical setting. Massively transfused patients will show evidence of defective hemostasis in a high percentage of cases. In this review, the term "coagulopathy" is used interchangeably with the more general term "defective hemostasis" and encompasses both defects of primary hemostasis (related to platelet function) and coagulopathy (related to alterations of the plasma phase of coagulation).

The incidence of hemostatic defects associated with MT will vary according to the clinical context (blunt $v s$ penetrating trauma, presence of brain injury, elective surgery),, 3 according to the definition of coagulopathy (clinical findings $v s$ laboratory test results), ${ }^{3}$ and according to the blood products administered to the massively bleeding patient (fresh whole blood, stored whole blood, "modified whole blood" (MWB-whole blood from which platelets and/or cryoprecipitate are salvaged before storage), ${ }^{4,5}$ packed red blood cells (PRBC), concentrated red cells, etc.). ${ }^{6}$ For example, prior to the era of blood fractionation, the transfusion of large volumes of stored blank blood did not result in a hemorrhagic diathesis in young and previously healthy soldiers wounded during the Vietnam war. ${ }^{7}$ More recently, it has been shown that abnormalities of the prothrombin time (PT) and of the activated partial thromboplastin time (aPTT) occur after the transfusion of 12 units of PRBC and that thrombocytopenia develops after the transfusion of 20 units. $^{8}$ Yet, despite several attempts at defining meaningful laboratory indicators of impending or established coagulopathy, the relationship between laboratory hemostatic abnormalities and abnormal clinical bleeding remains unclear.

Most studies of MT have been conducted in trauma patients and most are retrospective or uncontrolled observational studies, ${ }^{9}$ for obvious reasons. Given the variable and complex clinical context, the results of these studies have seldom led to definitive conclusions. Furthermore, factors other than the transfusion strategy, related to trauma itself, may have led to the observed hemostatic abnormalities. ${ }^{10}$ Unfortunately, conventional teaching has sometimes failed to appreciate the evolution of transfusion practices and the context in which these were developed. As a result, anesthesiologists may have been led to apply transfusion strategies, e.g., those developed for trauma patients at a time when MWB was available, ,,11 inappropriately to patient receiving red cell concentrates for massive bleeding during elective surgery. The situation may become even more confusing when disseminated intravascular coagulation (DIC) is associated with trauma and/or MT.

In this article on MT and coagulopathy, we will attempt to review:

- 1. the pathophysiology of coagulopathy in massively transfused, adult and previously hemostatically competent patients in both the elective surgical and trauma settings; and

- 2. the management strategies used in these settings.

We searched Medline for original articles published on "massive transfusion," "transfusion," "trauma," "surgery," "coagulopathy" and "hemostatic defects." In addition, the reference lists of obtained articles were searched to identify other relevant articles. This review does not deal with the obstetrical and pediatric patient populations, nor with specific hemostatic anomalies such as those associated with cardiopulmonary bypass $(\mathrm{CPB})$, liver transplantation and pre-existing coagulation disorders. Nevertheless, when relevant to the discussion, a few articles from those areas have been included in the review.

A preliminary version of the text was circulated to experts of the "Groupe d'intérêt en hémostase périopératoire" [Perioperative Hemostasis Interest Group] for comments and suggestions at a meeting of the GIHP held in La Fouly, Switzerland, in February 2003. A narrative format was adopted since the heterogeneity of published studies is considerable and was not conducive to a more formal review. Because the nature of blood products available to clinicians 
has changed over time, the retrieved articles were organized and reviewed by date of publication, to understand the evolution of our knowledge on MT and coagulopathy.

\section{Pathophysiology of coagulopathy in MT}

Volume replacement with crystalloids and colloids and temperature control are initial resuscitation measures; these are followed by the transfusion of red cells, coagulation factors and platelets; finally, DIC may become a problem that will require treatment.

\section{A. Hemodilution}

1. CRYSTALLOIDS

In elective surgery, rapid hemodilution with crystalloids has been shown to induce changes on thromboelastography suggestive of increased thrombin generation and a hypercoagulable state. ${ }^{12,13}$ The clinical significance of this effect, specially in trauma patients who are initially hypercoagulable, ${ }^{7}$ remains unclear. Nonetheless, crystalloid-induced hypercoagulability casts a doubt on studies of the effects of colloids on coagulation that used crystalloids as a control. ${ }^{14}$

\section{COLLOIDS}

The characteristics of the different colloids and their effects on coagulation are presented in Table I.

Gelatins have the reputation of not influencing coagulation other than by their hemodiluting effect. ${ }^{15,16}$ Nonetheless, dilution of whole blood samples with two gelatin solutions resulted in a reduction of clot quality (less extensive fibrin mesh formation, reduced clot weight and mean shear modulus) compared to dilution with normal saline. ${ }^{17}$ In volunteers, $1 \mathrm{~L}$ of a gelatin-based plasma substitute significantly impaired primary hemostasis and thrombin generation compared to normal saline. ${ }^{18} \mathrm{~A}$ study comparing a $3 \%$ modified fluid gelatin to $6 \%$ hydroxyethyl starch (HES) in patients undergoing primary total hip replacement concluded that the gelatin-based plasma expander had a poorer volume effect than HES and that blood losses were less important with gelatin compared to HES. ${ }^{15}$ Coagulation tests were similar in both groups except for the higher incidence of an abnormal bleeding time (BT) in the HES group. The clinical significance of these findings remains unclear. Perhaps the effects on coagulation of gelatin-based plasma substitutes are not clinically important. On the other hand, they may have been underestimated, given the difficulties of studying coagulation in the uncontrolled context of trauma, MT and ongoing bleeding.

HES solutions are effective plasma expanders in common use both in Europe and in North America.
It has long been known that HES solutions interfere with coagulation ${ }^{19}$ and that the effects vary according to the dose and type of solution administered. ${ }^{20}$ Solutions with a high molecular weight and a high degree of substitution accumulate in the tissues and are responsible for more pronounced hemostatic effects. ${ }^{21}$ Abnormal platelet function occurs more frequently after high molecular weight HES. ${ }^{22}$ Conversely, HES solutions with a low molecular weight and a lesser degree of substitution are eliminated more rapidly and tend to affect measures of hemostasis less. ${ }^{23-25}$

In addition to their effects on hemostasis, the infusion of large volumes of HES solutions will result in significant hemodilution. The resulting drop in hemoglobin and platelet concentrations may compromise primary hemostasis. In addition, Innerhofer et al. have shown that the administration of HES or modified gelatin in patients undergoing knee replacement surgery results in reduced clot strength due to impaired fibrinogen polymerization and that reduced fibrinogen concentrations might be reached earlier than expected. ${ }^{26}$

Adverse events associated with the use of HES solutions for the resuscitation of patients requiring MT have not been reported, inasmuch as the allowed maximal daily dose is not exceeded. ${ }^{16}$ A large retrospective study suggested that the use of $6 \%$ HES in primary cardiac surgery with CPB may increase bleeding and transfusion requirements, despite the infusion of volumes smaller than the manufacturer's recommended dose. ${ }^{27}$ Conversely, large volumes (up to $5 \mathrm{~L}$ ) have been infused without major complications, ${ }^{28}$ but the safety of this practice remains controversial. ${ }^{29}$

The clinical significance of the effects of HES solutions on hemostasis remains unclear. It may never be possible to determine precisely the effect of volume replacement in massively transfused patients with ongoing bleeding. In these patients, hemostasis is stressed severely by numerous factors other than the type of non-blood-related $i v$ fluid used for resuscitation and the underlying cause of coagulopathy is difficult to ascertain. Nonetheless, it is interesting to note that the use of colloids in trauma patients is not mentioned in the recommendations by the American College of Surgeons. ${ }^{30}$

\section{B. Hypothermia}

An important measure to reduce blood loss through preservation of hemostasis is the maintenance of normothermia both during and after the operation. The definition of hypothermia has varied amongst studies; however, most definitions have used temperatures below $35^{\circ} \mathrm{C}$. Hypothermia slows the activity of the coagulation cascade, an enzymatic process, reduces 
TABLE I Characteristics of the available colloids and their effects on coagulation

\begin{tabular}{|c|c|c|c|c|c|c|c|}
\hline Product & Commercial name & Concentration \% & $\begin{array}{l}\text { Oncotic pressure } \\
m m H g\end{array}$ & $\begin{array}{l}\text { Initial volume } \\
\text { expansion \% }\end{array}$ & $\begin{array}{l}\text { Persistance in the } \\
\text { body (days) }\end{array}$ & $\begin{array}{l}\text { Maximal } \\
\text { dose } / 24 \mathrm{hr}\end{array}$ & $\begin{array}{l}\text { Effect on } \\
\text { hemostasis }\end{array}$ \\
\hline Albumin & & 4 & $\begin{array}{l}20-29 \\
20\end{array}$ & $\begin{array}{l}80 \\
100-120\end{array}$ & $200-400$ & & 0 \\
\hline Dextran 70 & Macrodex & 6 & $56-68$ & 120 & $28-42$ & $1.5 \mathrm{~g} \cdot \mathrm{kg}^{-1}$ & +++ \\
\hline Dextran 40 & Rheomacrodex & 10 & $168-191$ & 200 & 6 & $1.5 \mathrm{~g} \cdot \mathrm{kg}^{-1}$ & +++ \\
\hline Fluid gelatin & Gelofusine, Plasmion & $3-4$ & 42 & $70-90$ & 7 & & 0 to + \\
\hline Urea linked gelatin & Hemacel & 3.5 & $25-29$ & $70-80$ & $2-7$ & & 0 to + \\
\hline HES $450 / 0.7$ & Plasmasteril & 6 & $24-30$ & 100 & $120-182$ & $20 \mathrm{~mL} \cdot \mathrm{kg}^{-1}$ & +++ \\
\hline HES $200 / 0.62 / 10$ & Elohes & 6 & $25-30$ & 110 & $6-7$ & $20 \mathrm{~mL} \cdot \mathrm{kg}^{-1}$ & ++ \\
\hline HES $200 / 0.5 / 5$ & Hesteril & 6 & $30-37$ & 100 & $3-4$ & $33 \mathrm{~mL} \cdot \mathrm{kg}^{-1}$ & + \\
\hline HES $200 / 0.5 / 5$ & Lomol, Hesteril & 10 & $59-82$ & 145 & $3-4$ & $20 \mathrm{~mL} \cdot \mathrm{kg}^{-1}$ & + \\
\hline HES $130 / 0.4 / 11$ & Voluven & 6 & 36 & $100-110$ & & $50 \mathrm{~mL} \cdot \mathrm{kg}^{-1}$ & 0 to + \\
\hline
\end{tabular}

Effect on hemostasis: $0=$ none; $+=$ weak $++=$ moderate $;+++=$ important. Commercial names are European. Some data are not available. In the "product" column, the first number is the molecular weight in Daltons, the second is the degree of substitution and the third is the $\mathrm{C} 2 / \mathrm{C} 6$ ratio of hydroxyethylstarch (HES) substitution. The higher the molecular weight and the degree of substitution, the longer the plasma half-life and the effects on hemostasis. Adapted from Ickx, BE and Van der Linden P. Interactions entre solutés colloides et l'hémostase. Sang Thrombose Vaisseaux 2002; 7: 408-16 [article in French] Hetastarch (480/0.7), used in the USA, has important effects on hemostasis. Pentastarch (260/0.45), available in Canada, is similar to Hesteril $10 \%$ and has weak effects on hemostasis at the maximal dose $\left(28 \mathrm{~mL} \cdot \mathrm{kg}^{-1}\right)$ recommended by the manufacturer.

the synthesis of coagulation factors, increases fibrinolysis and affects platelet function.

\section{ANIMAL DATA}

Several animal studies conducted under hypothermic conditions have shown reversible platelet count decreases and platelet function defects, altered coagulation patterns and an enhanced fibrinolytic response. In dogs cooled to $19^{\circ} \mathrm{C}$, Yoshihara et al. found a severe decrease in platelet count and collagen-induced platelet aggregability and an increase in fibrinolysis. ${ }^{31}$ No variations of the PT and aPTT were observed but these tests were performed in vitro at $37^{\circ} \mathrm{C}$. These modifications, which could potentially increase bleeding, were not documented in the normothermic control group. Other experimental studies have shown an important prolongation of the PT and aPTT that was inversely and linearly correlated to temperature. ${ }^{32,33}$

Pina-Cabral et al. also observed a decrease in platelet count in hypothermic dogs. ${ }^{34}$ The presence of platelet clumps was detected inside the hepatic sinusoids. The authors concluded that hepatic platelet sequestration could explain the decrease in platelet count in this setting.

In swine, Oung et al. showed a prolongation of the BT (10.9 min vs $5.5 \mathrm{~min}$ in the control group), confirming the impairment of hemostasis induced by hypothermia $\left(30^{\circ} \mathrm{C}\right) .{ }^{35}$ Prolongation of the $\mathrm{BT}$ has also been observed by Valeri et al. in baboons subjected to systemic hypothermia at $32^{\circ} \mathrm{C}$ and skin hypothermia at $27^{\circ} \mathrm{C} .{ }^{36}$

\section{HUMAN DATA}

In humans, many studies have emphasized the major role of hypothermia on the onset of bleeding during surgical procedures. Valeri et al. observed the effects of skin temperature in 33 patients undergoing $\mathrm{CPB} .{ }^{37}$ Local hypothermia produced an increased BT and a significant reduction in thromboxane $\mathrm{B} 2$, an indicator of platelet activation, at the BT site. Local rewarming produced a significant increase in shed blood thromboxane B2. Thus, hypothermia caused a reversible platelet dysfunction and rewarming improved platelet function and reduced the BT. These data have been confirmed by Michelson et al. who demonstrated the involvement of platelet glycoprotein receptor (GP Ib and GMP 140) alterations in this hemostatic defect. ${ }^{38}$ Again, rewarming completely reversed the activation defect as soon as temperature returned to $37^{\circ} \mathrm{C}$.

These abnormalities of routine coagulation tests are clinically significant: mild hypothermia $\left(35 \pm 0.5^{\circ} \mathrm{C}\right)$ increased bleeding and allogeneic blood requirements in patients undergoing total hip arthroplasty. ${ }^{39}$ Thus, surgery under normothermic conditions may help prevent bleeding complications and decrease the intraoperative use of transfusions. The additional contribu- 


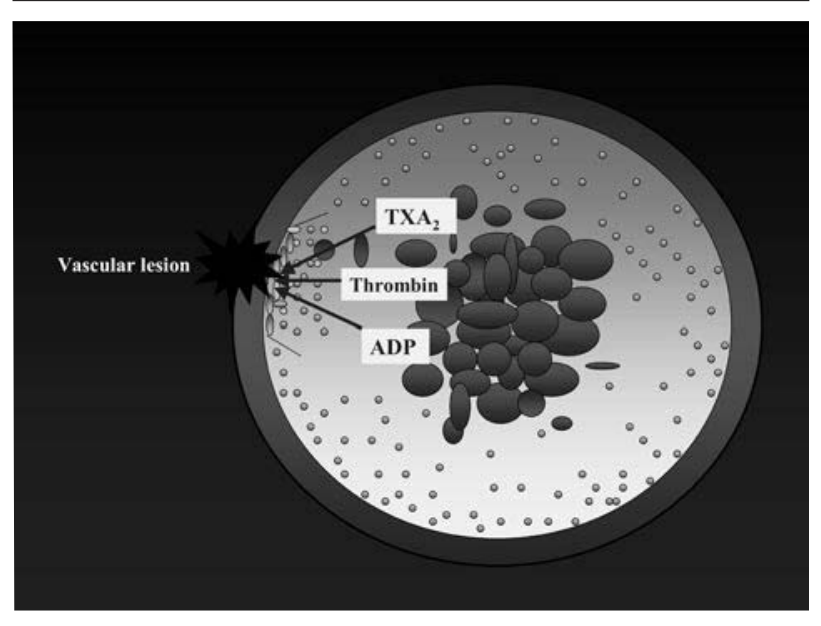

FIGURE 1 The contribution of red cells to hemostasis Red cells contribute to the margination of platelets against the vessel wall and their availability to act at the site of a vascular lesion. They have also been shown to modulate the biochemical and functional responsiveness of activated platelets. (Courtesy of Sylvain Bélisle, MD, FRCPC, Montreal Heart Institute).

tion of hypothermia to the hemorrhagic diathesis may be overlooked since coagulation testing is normally performed at $37^{\circ} \mathrm{C} .{ }^{40}$

Hypothermia is an important contributor to coagulopathy in trauma patients. ${ }^{41}$ Hypothermia (temperature less than $34^{\circ} \mathrm{C}$ ) occurred in $80 \%$ of non-survivors and $36 \%$ of survivors in the 45 trauma patients reported by Ferrara et al..$^{42}$ Patients who were hypothermic and acidotic developed clinically significant bleeding despite adequate blood, plasma, and platelet replacement. The authors concluded that avoidance or correction of hypothermia may be critical in preventing or correcting coagulopathy in the patient receiving MT.

\section{Blood components and alterations of hemostasis 1. RED CELLS}

An often-ignored effect of red blood cell (RBC) transfusion is the improvement of hemostatic function. The contributions of $\mathrm{RBC}$ to hemostasis are illustrated in Figure 1.

Erythrocytes have been shown to modulate the biochemical and functional responsiveness of activated platelets, suggesting that erythrocytes contribute to thrombosis and hemostasis and supporting the concept that thrombus formation is a multicellular event. ${ }^{43-45}$ Red cells contain adenosine diphosphate that may activate platelets. ${ }^{46}$ Also, they activate platelet cyclooxygenase, ${ }^{44}$ increase the generation of thromboxane $\mathrm{A} 2^{44}$ and may directly increase the thrombin burst through exposure of procoagulant phospholipids. ${ }^{47}$ This proaggregatory property of erythrocytes is enhanced by diabetes ${ }^{48}$ and can be decreased by an appropriate aspirin regimen. ${ }^{49,50}$

Another mechanism by which erythrocytes modulate hemostasis is the rheological effect of red cells on the margination of platelets. ${ }^{51}$ Under normal circumstances, red cell flow is maximal at the centre of a vessel, tending to push platelets towards the periphery of the vessel lumen, thereby optimizing their interaction with injured endothelium and promoting hemostasis. In rabbit arterioles, platelet numbers are highest near the vessel wall ${ }^{52}$ and platelets align themselves with their equatorial plane parallel to the vessel wall as they move closer toward the periphery of the vessel. ${ }^{53}$ Experimental data have shown that platelets are expelled toward the RBC depleted marginal layer near the tube wall by mutual interaction with erythrocytes. Under these circumstances, the near wall concentration of platelets is enhanced up to about seven times the average concentration. ${ }^{54}$

The correlation between the BT and hematocrit levels has been studied experimentally. In non-thrombocytopenic rabbits, the microvascular BT varied inversely with the hematocrit, animals with hematocrit levels above $35 \%$ having shorter BTs than animals with hematocrits lower than $35 \% .{ }^{55}$ In a rabbit model of cyclic arterial thrombosis and clot lysis, OuaknineOrlando et al. have shown that decreases in the hematocrit reduced the cyclic arterial thrombosis rate and increased the BT. ${ }^{46}$ Interestingly, normalization of the hematocrit caused thrombosis to reappear.

Transfusion of RBC shortens the BT in anemic thrombocytopenic patients despite persistent thrombocytopenia ${ }^{56}$ Further, perfusion of blood from transfused, previously anemic thrombocytopenic patients improved the interaction of platelets with the subendothelium in an experimental perfusion model. However, this interaction remained lower than in non-anemic non-thrombocytopenic subjects. ${ }^{56}$ Similarly, RBC shorten the $\mathrm{BT}$ and control the hemorrhagic diathesis of uremic patients. ${ }^{57}$ In humans with a normal renal function and platelet counts over $100,000 \cdot \mathrm{mm}^{-3}$, a modest but statistically significant inverse correlation $(\mathrm{r}$ $=-0.47 ; P<0.001)$ exists between the hematocrit and the BT. ${ }^{58}$ Patients with a pretransfusion hemoglobin concentration $\leq 60 \mathrm{~g} \cdot \mathrm{L}^{-1}$ have a greater chance (relative risk $4.07 ; 95 \%$ confidence interval 1.03 to $16.2 ; P=$ 0.04 ) of a posttransfusion decrease in BT than patients with a hemoglobin of more than $60 \mathrm{~g} \cdot \mathrm{L}^{-1} \cdot{ }^{59}$ Valeri et al. have shown that, in healthy volunteers, an acute $15 \%$ 
reduction in hematocrit produced a $60 \%$ increase in the $\mathrm{BT}$ while the $\mathrm{BT}$ remained normal despite a $32 \%$ reduction in platelet count. ${ }^{60}$ All this being said, the clinical significance of these findings remains unclear since the relationship between the $\mathrm{BT}$ and perioperative blood losses is highly controversial. ${ }^{60,61}$

The hemostatic effects of profound normovolemic hemodilution were investigated in eight patients undergoing surgical correction of idiopathic scoliosis by McLoughlin et al. ${ }^{62}$ Abnormal hemostasis developed prior to compromise of global tissue oxygenation suggesting that, in healthy anesthetized subjects, normovolemic hemodilution may be limited more by preservation of normal coagulation. In this report, reinfusion of all collected blood at the end of the procedure did not normalize the PT or the aPTT. Unfortunately, the authors did not describe if the microvascular bleeding (MVB) observed during hemodilution was corrected by increasing the hematocrit. Modified ultrafiltration in pediatric open heart operations has been shown to increase the hematocrit and attenuate the dilutional coagulopathy associated with $\mathrm{CPB}$ in infants. ${ }^{63}$ Use of modified ultrafiltration to increase the hematocrit to $36-42 \%$ reduced the rise in total body water and the need for donor blood in children undergoing open heart surgery. ${ }^{64}$

Thus, further investigations into the role of the hemoglobin concentration or hematocrit on hemostasis in massively transfused patients appear warranted. The data presented above tend to support the concept of a minimal hematocrit for optimal hemostasis. At present the optimal hematocrit or hemoglobin concentration to prevent or to initiate treatment of coagulopathy remains unknown. Experimental evidence suggests that relatively high hematocrits, possibly as high as $35 \%$, are required to sustain hemostasis in bleeding patients undergoing MT.

\section{COAGULATION FACTORS}

It is difficult to isolate precisely the role of coagulation factors in the pathophysiology of coagulopathy associated with MT. Impaired hemostasis is most probably multifactorial in origin and results from the adverse hemostatic effect of multiple concurrent coagulation factor deficits combined with variable degrees of anemia and thrombocytopenia. ${ }^{6}$

While numerous studies have measured changes in the PT and aPTT in relationship with bleeding and MT, few have examined individual hemostatic factors. In 1979, transfusing MWB to patients who sustained major trauma, massive gastrointestinal hemorrhage or aortic aneurysm rupture, Counts et al. reported that the number of units of blood transfused explained less than $20 \%$ of the variance in factors V and VIII and was not related to factor VII, X, XI, XII and fibrinogen levels. The authors concluded that it was not necessary to supplement transfusions of stored, MWB with fresh blood or fresh frozen plasma (FFP). ${ }^{5}$ In 1995, using plasma poor red cell concentrates, Hiippala et al. showed that a concentration of fibrinogen of 1.0 $\mathrm{g} \cdot \mathrm{L}^{-1}$ was reached when the blood loss was 1.42 times the calculated blood volume and that blood losses in excess of two blood volumes caused the deficiency of prothrombin, factor V, platelets and factor VII, in this order. ${ }^{65}$ These observations were made in ASA physical status I or II patients undergoing elective major urologic or abdominal surgery and, as a result, may not apply to emergent operations or trauma. Nonetheless, they illustrate well the difference between the times when red cell solutions contained significant amounts of plasma and modern component therapy.

It is important to realize that studies conducted at a time when fresh, stored or modified MWB was in common use seldom reported low levels of coagulation factors as the primary factor responsible for impaired hemostasis. ${ }^{4,5,7,11,66}$ Since the widespread use of red cell solutions containing minimal amounts of plasma in the late 1980's and early 1990's, dilution or consumption of coagulation factors has become a significant issue requiring specific treatment with, primarily, FFP. ${ }^{3,6,8,65}$ Even today, clinicians seldom administer "pure" blood products. PRBC contain a small amount of plasma (30$60 \mathrm{~mL}$ ), as do platelet concentrates $(80 \mathrm{~mL}$ approximately). Therefore, it may be difficult to differentiate precisely the therapeutic effect of the different blood components transfused.

\section{Platelets}

Primary hemostasis is characterized by the formation of the "platelet plug." The mechanism is complex and involves the presence of fibrinogen and activation of several glycoprotein receptors on platelets. ${ }^{67-71}$ Hemostasis is initiated by injury to the vascular wall, leading to the deposition of platelets adhering to blood vessel subendothelial matrix proteins (collagen and von Willebrand factor) via interactions with platelet membrane glycoprotein receptors. Subsequently, the GP IIb/IIIa receptor is activated. This receptor has a high affinity for fibrinogen (and also for von Willebrand factor at high shear stress). Binding of fibrinogen to adjacent platelets results in irreversible platelet aggregation and the formation of the platelet aggregate.

Since the publication of Miller's classic study on coagulation defects associated with massive blood transfusions, ${ }^{11}$ thrombocytopenia resulting from 


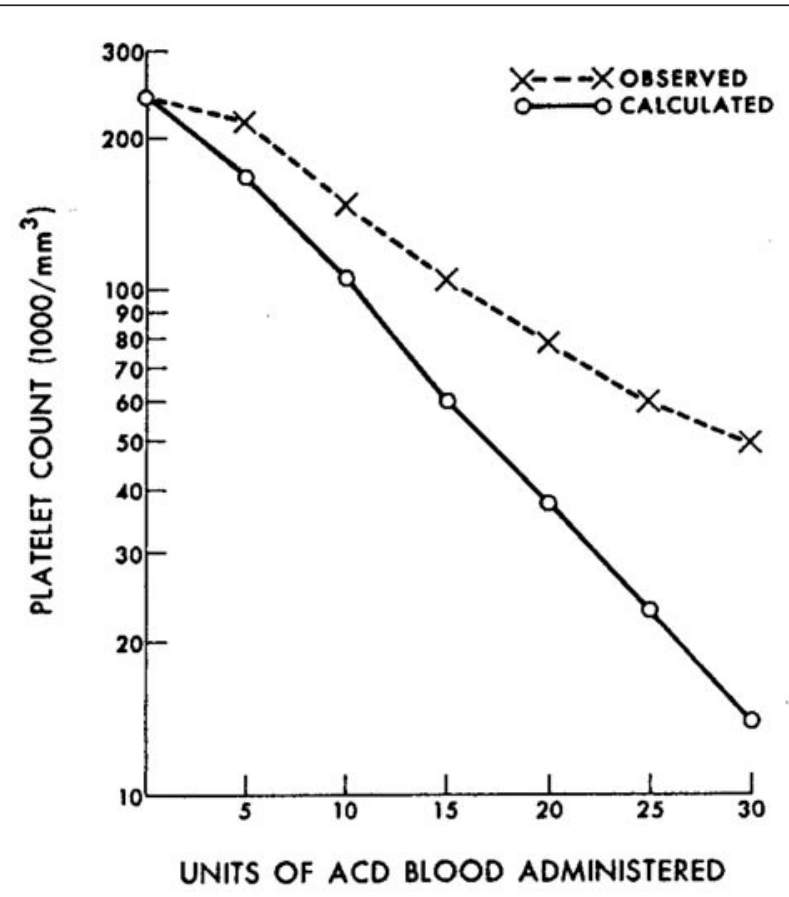

FIGURE 2 Calculated $v s$ observed platelet counts in a person receiving platelet-free blood

Observed platelet counts are higher than those predicted by hemodilution alone: the observed platelet count after the administration of 25 units of blood is of the order of $60,000 \cdot \mathrm{mm}^{-3}$ while hemodilution predicted a platelet count of approximately $20,000 \cdot \mathrm{mm}^{-3}$. Reproduced with permission from Miller RD, Robbins TO, Tong MJ, Barton SL. Coagulation defects associated with massive blood transfusions. Ann Surg 1971; 174: 794-801.

hemodilution has been thought to be the most important hemostatic abnormality associated with MT. This explanation is intuitively appealing: replacement of lost blood with fluids that do not contain platelets (or coagulation factors) results in a dilutional coagulopathy. However, models based on the washout equation (a simple mathematical model of exchange transfusion that calculates the decay of blood components when bleeding and replacement rates are constant and equal) may not apply to bleeding trauma patients where blood volumes fluctuate, bleeding rates vary with blood pressure, and replacement often lags behind blood loss. ${ }^{72}$ Clinically, simple hemodilution has failed to explain several observations.

In young, previously healthy soldiers with wounds excluding burns and head injuries, platelet levels fell rapidly to about $100,000 \cdot \mathrm{mm}^{-3}$ during rapid transfusion of stored whole blood and remained at that level after the first $6 \mathrm{~L}$ of stored whole blood. The PT, aPTT and fibrinogen levels were less severely affected and, most important, significant operative bleeding was not encountered in conjunction with these mild dilutional coagulation changes. ${ }^{7}$ On average, the platelet count fell below $100,000 \cdot \mathrm{mm}^{-3}$ after transfusion of 18 units of blood in the study by Counts et al., ${ }^{5}$ but slightly less than half $(43 \%)$ of the variation in platelet counts could be ascribed to the functional relationship between the amount of blood transfused and the platelet count. In a study conducted to determine the efficacy of prophylactic platelet administration to prevent MVB associated with MT, Reed et al. observed that platelet counts were not different between patients who received prophylactic platelet transfusions and those who did not. ${ }^{4}$ Further, both groups had higher platelet counts than predicted by a standard washout equation. This finding implies that platelets are being released into the circulation and counteract the effects of dilution. Sequestered platelets can be released from the spleen and the lung, in addition to the premature release of platelets from the bone marrow. Elevated stress hormones and the administration of catecholamines, a situation more likely to occur in the trauma patient, will influence release.

As in the study by Counts, Reed et al. found the relationship between platelet counts and units of blood transfused to be significant albeit highly variable $\left(\mathrm{r}^{2}=\right.$ 0.24 for patients receiving platelets and $\mathrm{r}^{2}=0.35$ for patients receiving FFP) ${ }^{4}$ suggesting that factors other than simple dilution affect platelet count. Finally, in the study by Miller, observed platelet counts did not parallel calculated platelet counts (Figure 2). ${ }^{11}$

In elective surgery, the situation appears to be quite different, possibly because tissue trauma is more controlled, normovolemia is maintained and blood losses are replaced in a timely manner. In this context, coagulopathy is primarily related to a coagulation factor deficit ${ }^{3,65}$ and the role of fibrinogen appears to be preponderant. The deficiency in fibrinogen concentration develops earlier than any other hemostatic abnormality when plasma-poor red cell concentrates and colloid plasma substitutes are used for the replacement of major blood loss. Approximately $90 \%$ of the variation in fibrinogen concentration is explained by blood loss and the critical level of $1.0 \mathrm{~g} \cdot \mathrm{L}^{-1}$ is reached when blood losses reach $142 \%$ (95\% confidence interval $117 \%-169 \%$ ) of the calculated blood volume. ${ }^{65}$ In this same study, thrombocytopenia (defined as a platelet count below $50,000 \cdot \mathrm{mm}^{-3}$ ) was a late occurrence and, to a great extent, quite variable from patient to patient. Murray et al. studied coagulation changes during crystalloid and PRBC replacement of major blood loss during elective surgery. ${ }^{73}$ Four out of 12 patients presented a coagulopathy. All patients 
TABLE II Diagnostic criteria for disseminated intravascular coagulation (DIC)

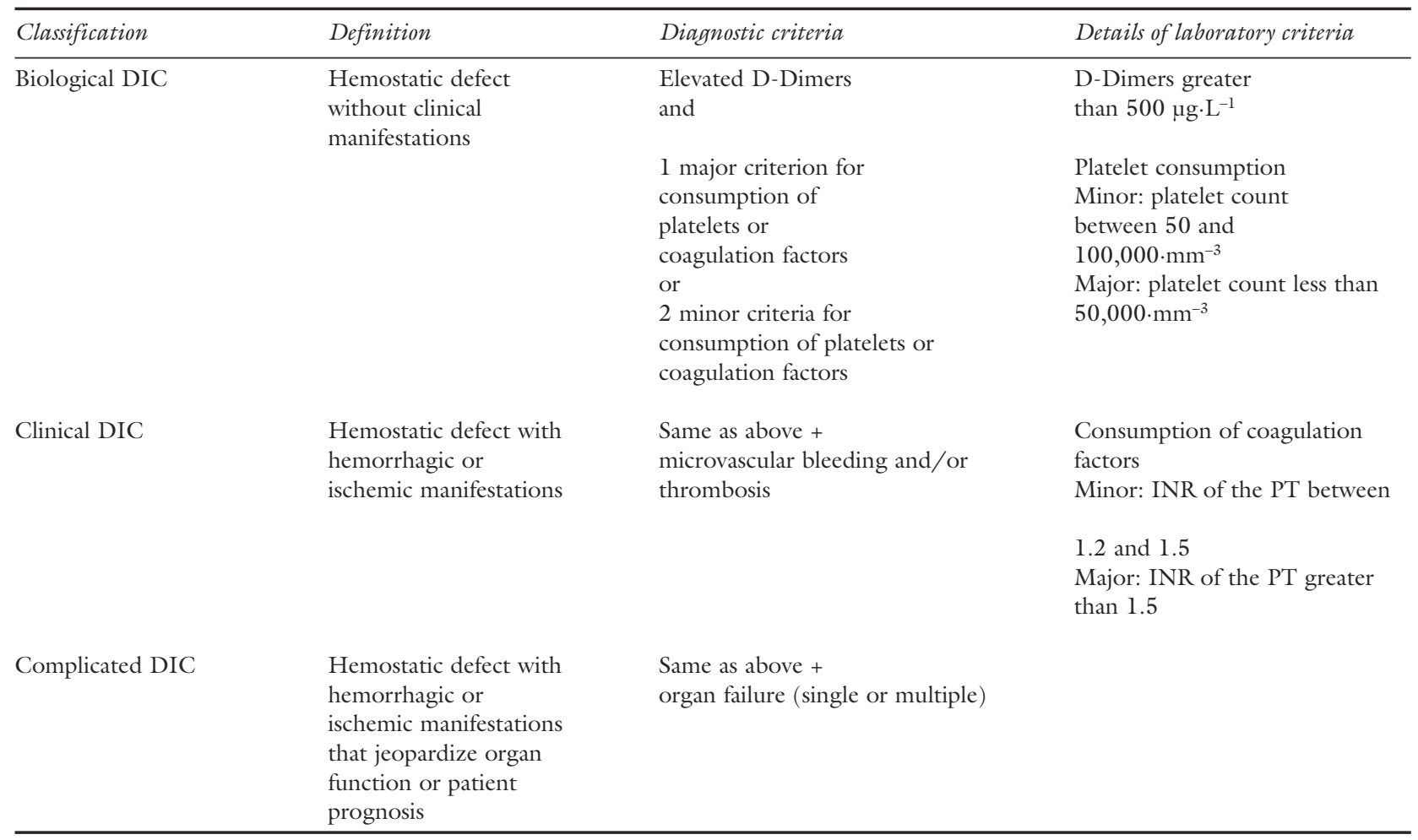

INR of the PT = international normalized ratio of the prothrombin time. The elevation of D-Dimers is not specific to DIC. Similarly, the clinical manifestations of DIC are not specific. Adapted from the Proceedings of the XXIInd consensus conference of the "Société de Réanimation de Langue Française" held in Lille, France, in October 2002 and published in Réanimation 2002; 11: 575-666. A French summary is available at www.srlf.org/conferences/XXII-conf-Lille.html.

with inadequate clinical hemostasis had a low platelet count $\left(83,000 \cdot \mathrm{mm}^{-3}\right.$ or below) and transfusion of platelet concentrates corrected the problem in the two who had fibrinogen concentrations above 1.0 $\mathrm{g} \cdot \mathrm{L}^{-1}$. Of note, platelet transfusion was ineffective in the two patients with concurrent low fibrinogen concentrations $\left(0.73\right.$ and $\left.0.40 \mathrm{~g} \cdot \mathrm{L}^{-1}\right)$. The subsequent transfusion of two and four units of FFP (respectively) normalized hemostasis. The report by Ciavarella et al. supports the association between MVB and a low platelet count (below $50,000 \cdot \mathrm{mm}^{-3}$ ) or a low fibrinogen concentration (below $0.5 \mathrm{~g} \cdot \mathrm{L}^{-1}$ ). ${ }^{66}$

Thus, it appears logical to consider that coagulopathy after MT can be a problem resulting from a combined deficit of platelets and fibrinogen. Focusing only on platelet levels or concentrations of specific coagulation factors may not lead to the most appropriate therapeutic approach.
D. DIC

1. DEFINITION

DIC is an acquired syndrome secondary to the systemic and excessive activation of coagulation. It may be defined by the association of hemostatic defects related to the exaggerated generation of thrombin and fibrin (with or without clinical signs) and the excessive consumption of platelets and coagulation factors. Criteria for the diagnosis of DIC are presented in Table II. The syndrome can be seen in numerous clinical situations and often complicates the management of MT.

\section{THE TRAUMA SETTING}

In earlier studies of trauma patients, DIC leading to MVB was, apparently, relatively infrequent, occurring for example in one out of 21 patients ${ }^{11}$ and three out of 27 patients. ${ }^{5}$ In wounded, previously healthy, soldiers requiring MT, DIC was mild and was not associated with clinical bleeding. ${ }^{7,11}$ Recent studies suggest that there is no significant correlation between total 
units of blood transfused and the severity of impaired hemostasis, suggesting that consumption of coagulation factors and platelets is more important than simple hemodilution. ${ }^{41,74,75}$

In trauma patients, two major mechanisms are responsible for the occurrence of DIC. The first relates to the nature and to the importance of tissue trauma. The second relates to shock and tissue anoxia. Brain injury is associated with a particularly high incidence of coagulopathy. In the study by Faringer et al., more than $40 \%$ of patients with penetrating or blunt trauma with associated brain injuries had abnormal coagulation tests on admission, compared with $0 \%$ in patients with blunt trauma but without brain injury. ${ }^{2}$ After blunt brain injury, a DIC syndrome secondary to the extravasation of tissue factor can rapidly (within one to four hours after injury) lead to a consumptive coagulopathy that is associated with a high frequency of death. ${ }^{76}$ Regarding the importance of tissue trauma, in the absence of massive head injury and pre-existing disease, life-threatening coagulopathy was associated with a $\mathrm{pH}$ of less than 7.10, a temperature of less than $34^{\circ} \mathrm{C}$, an injury severity score greater than 25 , and a systolic blood pressure of less than $70 \mathrm{mmHg}$. When all risk factors were present, the incidence of coagulopathy was $98 \%{ }^{41}$

At least two studies have attempted to determine which populations of massively transfused patients are most at risk of sustaining DIC. Mannucci et al. studied changes in the hemostatic system in 172 patients undergoing MT for excessive bleeding during or in the early postoperative period after elective, emergent or trauma surgery. Of these, 52 (30\%) suffered decompensated DIC and there was no significant relation between the number of whole blood or PRBC units transfused and the values of any variable of hemostasis measured. ${ }^{77}$ In a series of 64 patients receiving more than ten units of red cell concentrates during elective or urgent surgical procedures or resuscitation of multiple trauma, Hewson et al. observed that coagulopathy is related to hemodilution initially, but, within three hours, is related to the duration of antecedent hypotension. Thus, on the basis of the available information, it is difficult to determine which patient population (elective or urgent operations, trauma) is most likely to sustain DIC.

\section{THE ELECTIVE SURGICAL SETTING}

In the purely elective setting, DIC complicating MT is infrequent. No patient suffered from DIC amongst the 32 young ASA physical status I or II patients undergoing posterior spinal stabilization and $\mathrm{MT}^{3}$ Clinically increased surgical bleeding was present in 17 patients and in 14 of the 17 patients hemostasis improved after the administration of FFP (approximately $10 \mathrm{~mL} \cdot \mathrm{kg}^{-1}$ ). Again, these results suggest that when tissue anoxia is avoided and surgical trauma is controlled, the occurrence of DIC may remain low despite MT.

\section{Management of coagulopathy in MT A. Diagnosis}

Numerous attempts have been made to monitor changes of the coagulation system in relationship to trauma, surgery and MT. Unfortunately, results have been disappointing and, at present, there is no simple, reliable and rapid diagnostic test that allows clinicians to manage massively transfused, critically ill patients. The available tests quantify specific factors in clotting or attempt to measure clotting function.

The platelet count is the only indicator of coagulation that can be obtained rapidly through the use of automated counters, in contrast to conventional tests of hemostasis that take a minimum of 30 min since they require centrifugation of blood samples. Even if platelets play an important role in coagulation, a decreased platelet count is not a specific indicator of coagulopathy. Rather, the significance of a decreased platelet count should be interpreted in the patient's specific clinical context: is platelet function expected to be normal? Is the fibrinogen concentration sufficient? Is the hemoglobin concentration adequate? Is there any evidence of a consumptive coagulopathy? Answering these questions will assist in making the appropriate diagnosis of coagulopathy.

Usefulness of the BT to diagnose or predict coagulopathy in massively transfused patients has been investigated in a few studies. Overall, the BT increases early in the course of surgery and transfusion, ${ }^{78}$ remains elevated for several days postoperatively ${ }^{79}$ and does not allow the differentiation between bleeding and non-bleeding patients. ${ }^{5}$ In their critical reappraisal of the BT, Rodgers and Levin concluded that there is no evidence that abnormalities in the test occur sufficiently in advance of other indicators of bleeding to allow actions to be taken that could alter outcome favourably. ${ }^{80}$ Consequently, the BT is of no use in the context of MT.

Reliable bedside monitors have become available to monitor the PT and $\mathrm{APTT}^{81}$ and may add to the timely management of the bleeding patient. Controversy remains, though, on the proper use of coagulation screening tests to guide replacement therapy. The PT and aPTT are expected to become elevated when levels of factor V, VIII and IX are less than $50 \%$ of values found in a control patient population. ${ }^{82}$ It should be noted, however, that the PT and aPTT are prolonged 
TABLE III Proposals for the administration of hemostatic blood products in the massively transfused patient

\begin{tabular}{|c|c|c|c|}
\hline & \multicolumn{3}{|c|}{ Presence of clinical bleeding } \\
\hline & & Yes & No \\
\hline & Yes & $\begin{array}{l}\text { Transfusion of FFP and PC } \\
\text { according to the results of } \\
\text { coagulation testing }\end{array}$ & $\begin{array}{l}\text { Possible transfusion of FFP } \\
\text { and PC if the hemorrhagic risk } \\
\text { related to the surgical procedure is }\end{array}$ \\
\hline & & & high \\
\hline \multirow[t]{3}{*}{$\begin{array}{l}\text { Abnormal } \\
\text { coagulation tests* }\end{array}$} & No & $\begin{array}{l}\text { Search for a cause other than a } \\
\text { hemostatic defect }\end{array}$ & No indication to transfuse \\
\hline & & $\begin{array}{l}\text { Re-evaluate the importance of } \\
\text { red cell transfusion and } \\
\text { consider FFP and PC if } \\
\text { transfusion is massive } \\
\text { Repeat coagulation tests }\end{array}$ & \\
\hline & Unknown & $\begin{array}{l}\text { Transfusion guided by clinical } \\
\text { probability of a specific hemostatic defect }\end{array}$ & $\begin{array}{l}\text { No indication to transfuse } \\
\text { Obtain coagulation tests }\end{array}$ \\
\hline
\end{tabular}

* Platelet count less than $50,000 \cdot \mathrm{mm}^{-3}$, fibrinogen concentration less than $1.0 \mathrm{~g} \cdot \mathrm{L}^{-1}$, prothrombin time (PT) and activated partial thromboplastin time (aPTT) more than 1.5 to 1.8 times control. FFP = fresh frozen plasma; PC = platelet concentrate. Adapted from the recommendations of the "Agence française de sécurité sanitaire des produits de santé" for the transfusion of allogeneic red cells published in Transfusion clinique et biologique 2002; 9: 333-56 (article in French).

when fibrinogen levels are low in the presence of normal concentrations of coagulation factors (e.g., congenital afibrinogenemia).

As for decreased platelet counts and prolongations of the BT, prolongations of the PT and aPTT are very common in massively transfused patients. ${ }^{2,3,5,7,8,11,41,6}$ $5,73,75,77,83,84$ Minor prolongations of the PT or aPTT ratio (ratio $=$ measured value $/$ control value) are poor predictors of bleeding in massively transfused patients. ${ }^{5}$ Ciavarella et al. have shown that, in 36 massively transfused patients, patients with a PT or aPTT ratio greater or equal to $1.8 \mathrm{had}$ an 80 to $85 \%$ chance of exhibiting MVB. ${ }^{66}$ When the fibrinogen level is adequate, a PT or aPTT ratio greater or equal to 1.8 reliably predicts that factor V and VIII levels are less than $30 \%,{ }^{66}$ a percentage that has been cited as an indication for coagulation factor replacement. ${ }^{4,66}$ In the presence of a decreased fibrinogen concentration (less than $0.75 \mathrm{~g} \cdot \mathrm{L}^{-1}$ ), a PT or aPTT ratio greater than 1.5 is associated with factors $\mathrm{V}$ and VIII of less than $20 \% .^{73}$

In summary, only marked prolongations of the PT or aPTT ( 1.5 and 1.8 times higher than control when the fibrinogen level is low and normal respectively) are likely to be significant from a clinical perspective.

Other instruments have been developed to study coagulation at the bedside, using whole blood. While their use in the context of MT appeared promising, results have, unfortunately, been disappointing. The best known is the thromboelastograph, a device that measures the viscoelastic properties of the clot during its formation and subsequent lysis. In general surgical patients, thromboelastography analysis showed a trend toward increased coagulability with progressive blood loss and contributed to the identification of two patients who required treatment of a coagulopathy. ${ }^{85}$ Thromboelastography has a high negative predictive value $(82 \%)$ for bleeding after routine cardiac surgery, allowing the differentiation between surgical bleeding and coagulopathy. Unfortunately, the positive predictive value of the test is low (41\%). ${ }^{86}$ More studies will be required to establish its usefulness in the management of MT.

Another instrument, the PFA-100® (Platelet Function Analyzer; Dade-Behring, Miami, FL, USA), measures an ex-vivo BT in the presence of different agonists. The device has been used extensively for the diagnosis of hereditary coagulation disorders, particularly von Willebrand's disease. In patients undergoing routine cardiac operations, the PFA was not correlated with mediastinal chest drainage. ${ }^{87,88}$ A Medline search on the use of the PFA during MT failed to retrieve any relevant references.

\section{B. Treatment of coagulopathy}

The treatment of coagulopathy associated with MT is not simple. Two approaches are outlined in Table III and in Figure 3. Both approaches should be viewed as complementary. 


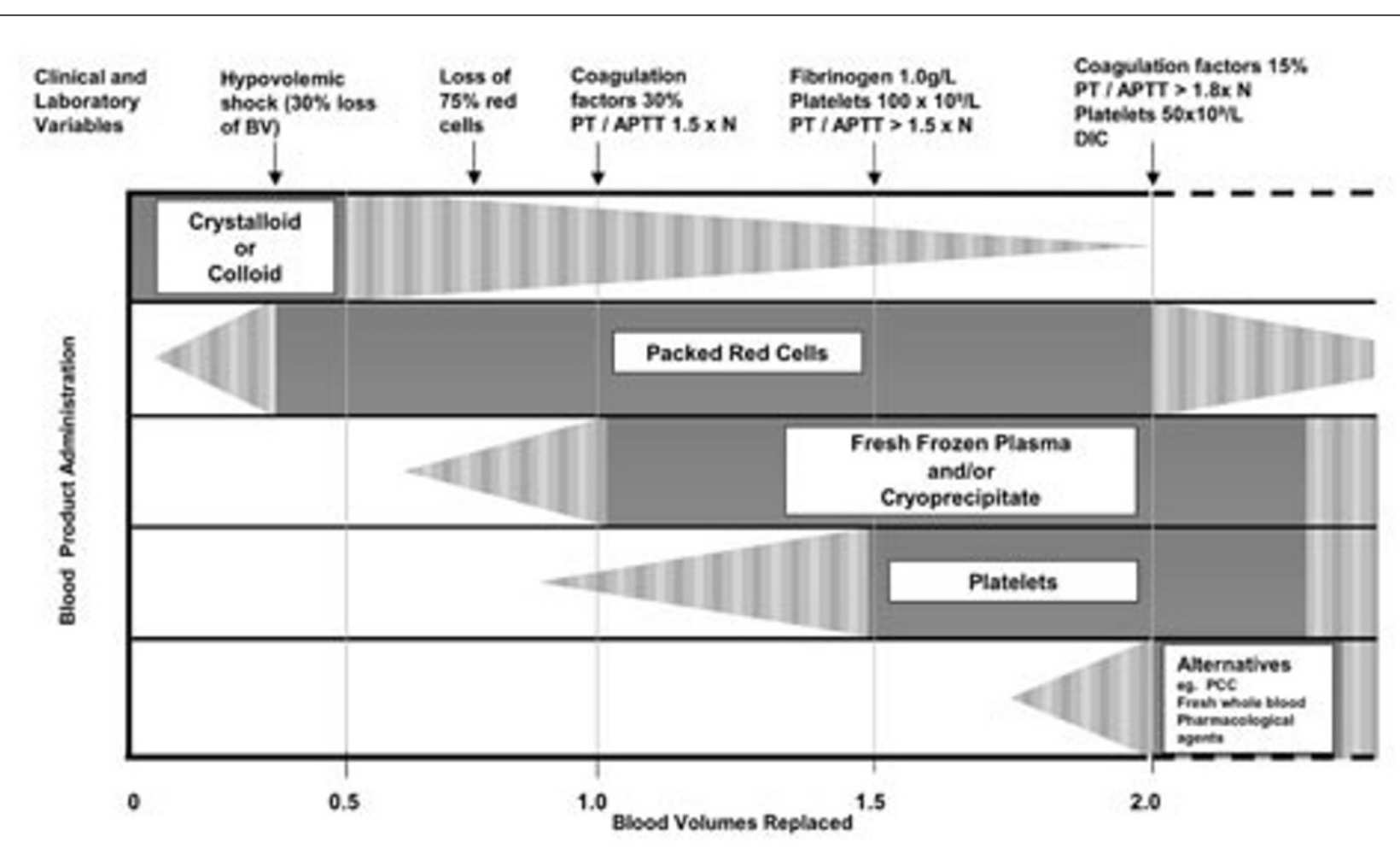

FIGURE 3 The management of massive transfusion in the elective surgical setting

Reproduced with permission from Erber WN. Massive blood transfusion in the elective surgical setting. Transfus Apheresis Sci 2002; 27: 83-92.

\section{GOALS OF TREATMENT}

The causal diagnosis of MVB remains elusive and the clinician must intervene rapidly if the patient is to survive. The situation is further complicated by the management of risks associated with transfusion, mandating that patients receive the smallest number of blood products possible. In Canada, in the year 2000 , the risk of human immunodeficiency virus and hepatitis $\mathrm{C}$ virus transmission was minimal: one in four million and one in three million, respectively. ${ }^{89}$ However, the aggregate risk of potentially severe reactions was much higher: 43.2 per 100,000 red cell units and 125.7 per 100,000 platelet pools of five units, affecting 337 and 88 recipients, respectively. ${ }^{89}$ The most frequent potentially severe outcomes were hemolytic reactions and volume overload for red cell transfusion and major allergic reactions and bacterial contamination for platelet transfusion. ${ }^{89}$

In general, clinicians assume that all blood products are comparable and that the conclusions of studies conducted in similarly developed countries can be applied locally. We compared the characteristics of blood products (PRBC, FFP and platelet concentrates) available in Canada and in three European countries (Belgium, France and Switzerland; characteristics of allogeneic blood products available as Additional Material at www.cja-jca.org). While some differences exist, these are minor and unlikely to result in clinically significant management disparities (Douglas Fish, personal communication).

In light of the above risks, we recommend that blood products be transfused to correct a physiologic deficit likely to be detrimental to the patient. Obviously, this is, most often, not possible in the context of MT, in the presence of ongoing hemorrhage for example. Hemostatic blood components should be transfused mainly to treat a clinical coagulopathy, unless important surgical factors justify transfusion, e.g., prior to invasive procedures in patients with a known hemostatic defect, in neurosurgical procedures where bleeding may have catastrophic consequences, etc., (note that the latter recommendations are based on expert opinion only).

No prophylactic regimen involving the administration of FFP and/or platelet concentrates has 


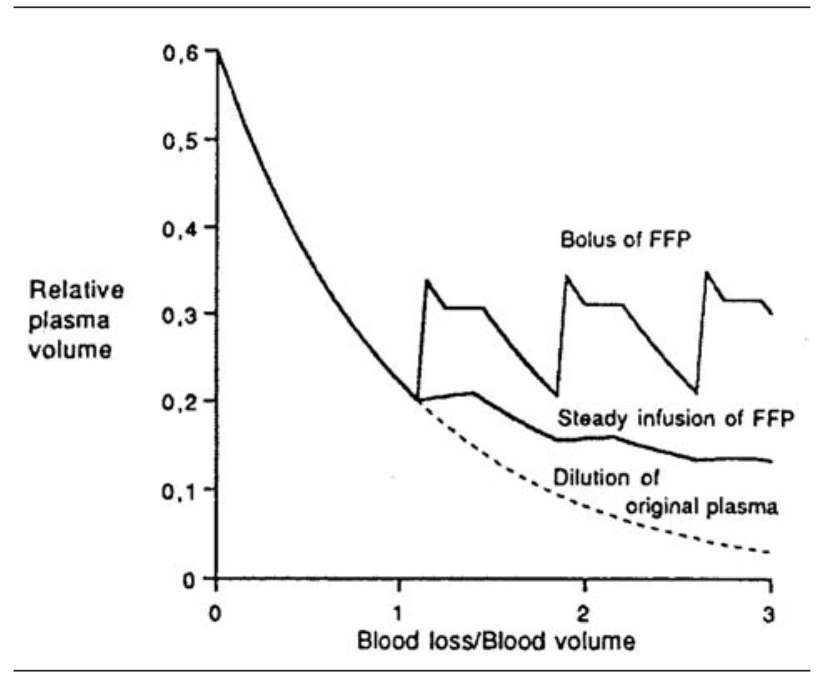

FIGURE 4 Simulation of relative plasma volume according to mode of fresh frozen plasma (FFP) supplementation

Reproduced with permission from Hiippala $S$. Replacement of massive blood loss. Vox Sang 1998; 74: 399-407.

been shown to be effective in massively transfused patients. ${ }^{4,5,77}$ The prophylactic administration of (potentially) unnecessary transfusions exposes patients to multiple donors, increases the risks to the patient and is unacceptable. ${ }^{90,91}$ Nonetheless, given the delay required to prepare and/or obtain blood products, MT associated with evidence of an evolving laboratory coagulopathy may warrant ordering of blood components that will, then, be readily available to treat MVB should it occur. ${ }^{92,93}$ Whenever possible, the use of single donor plasma or platelets is preferred to decrease donor exposure.

\section{APPROACHES TO THE TREATMENT OF COAGU- LOPATHY}

Figure 3, by Erber et al., summarizes well the use of blood and non-blood products involved in the resuscitation of a bleeding patient. ${ }^{94}$ Initially, crystalloids or colloids are infused to maintain normovolemia. As the percentage of blood volumes lost and replaced increases, PRBC, FFP and platelets will be required, in that order, guided by clinical and laboratory variables. Pharmacological agents are usually administered relatively late in the process [protamine sulfate antagonizes the effect of excess heparin; desmopressin has been used to control hemorrhage, specially after cardiac surgery, with varying success; aprotinin has been suggested in the context of trauma and MT but its use is not supported by any controlled trial; recombinant activated factor VII (rFVIIa) is a promising hemostatic agent under investigation but the optimal timing of administration of rFVIIa remains to be determined]. While this scheme is appealing and applicable in the elective surgical setting where bleeding is usually progressive and coagulopathy can be monitored and anticipated, the situation can be quite different in the traumatized patient.

In the interval between injury and arrival to the hospital, the trauma patient has lost an undefined amount of blood that has been replaced, in part, by crystalloids or colloids. ${ }^{72}$ Tissue trauma, shock, tissue anoxia and hypothermia contribute to the development of DIC and the results of coagulation testing are not immediately available. Clinicians are called upon to intervene rapidly in a very unclear and unstable situation.

Basic recommendations include the maintenance of normothermia and correction of a low hemoglobin concentration. Maintaining a normal body temperature is a relatively simple and probably one of the most effective strategies of blood conservation. Unfortunately, it can easily be overlooked in the trauma setting. When a hypothermic patient bleeds without an apparent surgical cause, restoration of temperature towards normal should be a first-line intervention. Correction of the hypothermia-induced hemostatic defect can be expected as soon as the patient is rewarmed.

A low hemoglobin concentration should be corrected prior to the administration of hemostatic blood products, in view of normalizing hemostasis in bleeding patients. When circumstances allow, allogeneic RBC should be transfused one unit at a time and the effects of transfusion on hemostasis monitored before administering supplemental units. The optimal hemoglobin concentration to sustain hemostasis in the context of MT remains unknown but is probably higher than that required for oxygen transport and delivery.

The use of platelets and/or FFP should depend on the results of coagulation testing and clinical judgment. A markedly prolonged PT and aPTT suggests a coagulation factor deficiency and is best treated with FFP. Decreased levels of fibrinogen will also require treatment with FFP. FFP should be administered in doses large enough to increase coagulation factor levels and maintain them above critical levels. Doses ranging from 5 to $20 \mathrm{~mL} \cdot \mathrm{kg}^{-1}$ have been recommended. In the average adult, four units of FFP (800 to 1,000 $\mathrm{mL}$ ) should suffice initially but additional bolus doses should be administered according to ongoing blood losses and transfusions. ${ }^{6}$ As shown in Figure 4 , it is important to administer sufficient bolus doses of FFP to maintain adequate concentrations of coagulation factors. Further, using a three compartment dynamic computer simulation, Hirshberg et al. suggest that, in 
TABLE IV Massive transfusion: the main differences between elective surgery and trauma

\begin{tabular}{|c|c|c|}
\hline & Elective surgery & Trauma \\
\hline Tissue trauma & Controlled & Massive and uncontrolled \\
\hline $\begin{array}{l}\text { Initiation of massive } \\
\text { transfusion }\end{array}$ & $\begin{array}{l}\text { No delay between hemorrhage } \\
\text { and initiation of treatment }\end{array}$ & $\begin{array}{l}\text { The interval between } \\
\text { hemorrhage and treatment can } \\
\text { vary widely }\end{array}$ \\
\hline Volume status/shock & $\begin{array}{l}\text { Normovolemia is maintained } \\
\text { and shock is avoided }\end{array}$ & $\begin{array}{l}\text { Hypovolemia and shock are } \\
\text { frequent }\end{array}$ \\
\hline Temperature & Normothermia is maintained & Hypothermia is frequent \\
\hline Monitoring of hemostasis & $\begin{array}{l}\text { Ongoing. Anticipation of } \\
\text { hemostatic defects is possible }\end{array}$ & $\begin{array}{l}\text { Late. Laboratory tests are } \\
\text { obtained when coagulopathy is installed }\end{array}$ \\
\hline Treatment of coagulopathy & $\begin{array}{l}\text { Correction of anemia } \\
\text { FFP and platelets as } \\
\text { determined by laboratory tests }\end{array}$ & $\begin{array}{l}\text { Correction of tissue } \\
\text { hypoperfusion } \\
\text { Correction of hypothermia } \\
\text { Correction of anemia } \\
\text { Platelets and FFP } \\
\text { as determined by laboratory tests }\end{array}$ \\
\hline
\end{tabular}

trauma patients with exsanguinating hemorrbage, FFP should be given rapidly (with the first units of PRBC replacement) in order to effectively prevent dilutional coagulopathy. ${ }^{72}$

If the fibrinogen concentration remains below 1.0 g. $\mathrm{L}^{-1}$ despite therapy with FFP, the administration of cryoprecipitate, a concentrated source of fibrinogen, factor VIII, factor XIII and von Willebrand factor may be indicated ${ }^{95}$ despite the associated infectious risks (ten to 20 units - containing $5 \mathrm{~mL}$ each - will be required). In Europe specially, cryoprecipitates are no longer available and, when fibrinogen substitution is required, virus-inactivated fibrinogen preparations are administered.

Platelets should be administered to correct a clinical coagulopathy associated with a decreased platelet count and/or platelet function. Clinicians must remember that platelet counts will decrease in a majority of massively transfused patients but that not all patients will bleed excessively as a result of thrombocytopenia. Other hemostatic anomalies may warrant a more urgent (a marked prolongation of the $\mathrm{PT}$ and aPTT) or concurrent (a decreased fibrinogen level) correction.

From the time PRBC have replaced whole blood, there is laboratory and clinical evidence in the literature that FFP may be required prior to platelet concentrates to treat a coagulopathy. ${ }^{3,6,8,73}$ On the other hand, two studies have shown that survival in massively transfused trauma patients is associated with the increased transfusion of platelet concentrates. ${ }^{41,96}$ One may postulate that a more aggressive control of coagulopathy was beneficial in these patients, a situation somewhat analogous to the benefits derived from early goal-directed therapy in patients with severe sepsis and septic shock. ${ }^{97}$ Unfortunately, at present, no monitor allows clinicians to identify which patient is likely to benefit from the increased transfusion of hemostatic blood components (such as platelets or FFP).

Several animal experiments, case reports and case series report the successful use of rFVIIa to treat bleeding that could not be controlled by the administration of hemostatic blood components. ${ }^{98-106}$ Originally, rFVIIa was developed to treat hemophiliacs with inhibitors to exogenous factor VIII and its use has been extended to the correction of several hemostatic defects. ${ }^{107}$ Since factor VII must interact with tissue factor to initiate the generation of thrombin, coagulation occurs at the site of injury ${ }^{108}$ and the risk of thromboembolic effects appears minimal. ${ }^{109}$ The initial results with this novel hemostatic agent for "rescue" therapy of MVB are impressive and warrant the conduct of randomized controlled trials to evaluate further the efficacy and safety of this expensive drug. ${ }^{110,111}$ 


\section{Conclusions}

Our first objective was to review the pathophysiology of coagulopathy in massively transfused, adult and previously hemostatically competent patients in both the elective surgical and trauma settings. The pathophysiology is complex and coagulopathy associated with MT requires a multidisciplinary approach involving anesthesiologists, blood bankers, hematologists, laboratory specialists and surgeons. In the trauma patient, DIC secondary to tissue injury and anoxia often complicates the management of MT. As a result, it is often difficult to ascertain the exact cause of MVB. The "classic" view that thrombocytopenia is responsible for the majority of bleeding complications in massively transfused patients should be abandoned. ${ }^{33}$ As we have seen, decreased levels of platelets and coagulation factors cannot be predicted by dilution alone. Coagulopathy associated with MT and surgery is an intricate, multicellular and multifactorial event. While the interaction between platelets, fibrinogen and red cells is particularly important, the contribution of fluid replacement therapy, hypothermia and coagulation factor deficiency must not be overlooked.

Our second objective was to review the evidence for strategies used to manage coagulopathy in both the elective surgical and trauma settings. Whether for elective surgery or for the management of trauma patients, reliable bedside monitors of hemostasis are needed urgently. By assisting clinicians in making the correct diagnosis in a timely manner, monitors will contribute to the optimal use of blood products.

Times have changed, blood products have changed, and so has the management of the bleeding patient. Therapy should take into account all the factors known to affect hemostasis in these patients. Transfusion of blood components should be based on appropriate hematological testing and initiated mainly in those patients who bleed actively. Nevertheless, a standardized management of MVB may not always be possible in massively bleeding patients, especially in the context of trauma.

The situation appears to be different in the elective surgical situation. Tissue trauma is more controlled, normovolemia can usually be maintained, tissue anoxia is avoided and there is more time to monitor coagulation variables and anticipate deficits. In this context, coagulopathy is more often related to decreased coagulation factors and best treated initially with FFP. The main differences between elective surgery and trauma are summarized in Table IV.

Finally, anesthesiologists tend to focus on hemorrhage and MT that occur as an immediate consequence of trauma or surgery. Yet, two other important consid- erations should be kept in mind. First, it is important to realize that many pre-existing bleeding disorders are clinically silent and only manifest at times of hemostatic stress such as trauma and major surgery. ${ }^{112}$ Thus, a postoperative assessment may be warranted in patients with a history or clinical examination suggestive of such a bleeding disorder. Second, in the postoperative period, many of these patients will experience thrombotic complications ${ }^{112}$ related to the consumption of coagulation factors associated with DIC. Once the initial, hemorrhagic, phase of coagulopathy is controlled, efforts should be directed towards the prevention of later, potentially disastrous thrombotic complications. Only then will the management of coagulopathy associated with MT be complete.

\section{References}

1 Crosson JT. Massive transfusion. Clin Lab Med 1996; 16: 873-82.

2 Faringer PD, Mullins RJ, Johnson RL, Trunkey DD. Blood component supplementation during massive transfusion of AS- 1 red cells in trauma patients. J Trauma 1993; 34: 481-5; discussion 485-7.

3 Murray DJ, Pennell BJ, Weinstein SL, Olson JD. Packed red cells in acute blood loss: dilutional coagulopathy as a cause of surgical bleeding. Anesth Analg 1995; 80: 336-42.

4 Reed RL, Ciavarella D, Heimbach DM, et al. Prophylactic platelet administration during massive transfusion. A prospective, randomized, double-blind clinical study. Ann Surg 1986; 203: 40-8.

5 Counts RB, Haisch C, Simon TL, Maxwell NG, Heimbach DM, Carrico CJ. Hemostasis in massively transfused trauma patients. Ann Surg 1979; 190: 91-9.

6 Hiippala S. Replacement of massive blood loss. Vox Sang 1998; 74(Suppl 2): 399-407.

7 Simmons RL, Collins JA, Heisterkamp CA 3rd, Mills DE, Andren R, Phillips LL. Coagulation disorders in combat casualties. I. Acute changes after wounding. II. Effects of massive transfusion. III. Post-resuscitative changes. Ann Surg 1969; 169: 455-82.

8 Leslie SD, Toy PT. Laboratory hemostatic abnormalities in massively transfused patients given red blood cells and crystalloid. Am J Clin Pathol 1991; 96: 770-3.

9 Stainsby D, MacLennan S, Hamilton PJ. Management of massive blood loss: a template guideline. $\mathrm{Br} \mathrm{J}$ Anaesth 2000; 85: 487-91.

10 Guay J, Ozier $\Upsilon$, de Moerloose P, Samana CM, Belisle $S$, Hardy JF. Polytrauma and hemostatic anomalies (French). Can J Anaesth 1998; 45: 683-91.

11 Miller RD, Robbins TO, Tong MJ, Barton SL. 
Coagulation defects associated with massive blood transfusions. Ann Surg 1971; 174: 794-801.

$12 \mathrm{Ng} \mathrm{KF,} \mathrm{Lam} \mathrm{CC,} \mathrm{Chan} \mathrm{LC.} \mathrm{In} \mathrm{vivo} \mathrm{effect} \mathrm{of} \mathrm{haemo-}$ dilution with saline on coagulation: a randomized controlled trial. Br J Anaesth 2002; 88: 475-80.

13 Ruttmann TG, James MF, Finlayson J. Effects on coagulation of intravenous crystalloid or colloid in patients undergoing peripheral vascular surgery. $\mathrm{Br} \mathrm{J}$ Anaesth 2002; 89: 226-30.

14 Ruttmann TG. Haemodilution enhances coagulation. Br J Anaesth 2002; 88: 470-2.

15 Mortelmans YJ, Vermaut G, Verbruggen AM, et al. Effects of 6\% hydroxyethyl starch and 3\% modified fluid gelatin on intravascular volume and coagulation during intraoperative hemodilution. Anesth Analg 1995; 81: 1235-42.

16 Samama CM. Traumatic emergencies and hemostasis (French). Cah Anesthesiol 1995; 43: 479-82.

17 Mardel SN, Saunders FM, Allen H, et al. Reduced quality of clot formation with gelatin-based plasma substitutes. Br J Anaesth 1998; 80: 204-7.

18 de Jonge E, Levi M, Berends F, van der Ende AE, ten Cate JW, Stoutenbeek CP. Impaired haemostasis by intravenous administration of a gelatin-based plasma expander in human subjects. Thromb Haemost 1998; 79: 286-90.

19 Strauss RG. Review of the effects of hydroxyethyl starch on the blood coagulation system. Transfusion 1981; 21: 299-302.

20 Traylor RJ, Pearl RG. Crystalloid versus colloid versus colloid: all colloids are not created equal. Anesth Analg 1996; 83: 209-12.

21 de Jonge E, Levi $M$. Effects of different plasma substitutes on blood coagulation: a comparative review. Crit Care Med 2001; 29: 1261-7.

22 Boldt J, Muller M, Heesen M, Heyn O, Hempelmann $G$. Influence of different volume therapies on platelet function in the critically ill. Intensive Care Med 1996; 22: 1075-81.

23 Boldt J, Haisch G, Suttner S, Kumle B, Schellhaass A. Effects of a new modified, balanced hydroxyethyl starch preparation (Hextend) on measures of coagulation. Br J Anaesth 2002; 89: 722-8.

24 Strauss RG, Pennell BJ, Stump DC. A randomized, blinded trial comparing the hemostatic effects of pentastarch versus hetastarch. Transfusion $2002 ; 42$ : 27-36.

25 Langeron $O$, Doelberg $M$, Ang ET, Bonnet F, Capdevila $X$, Coriat P. Voluven, a lower substituted novel hydroxyethyl starch (HES 130/0.4), causes fewer effects on coagulation in major orthopedic surgery than HES 200/0.5. Anesth Analg 2001; 92 : 855-62.
26 Innerhofer P, Fries D, Margreiter J, et al. The effects of perioperatively administered colloids and crystalloids on primary platelet-mediated hemostasis and clot formation. Anesth Analg 2002; 95: 858-65.

27 Knutson JE, Deering JA, Hall FW, et al. Does intraoperative hetastarch administration increase blood loss and transfusion requirements after cardiac surgery? Anesth Analg 2000; 90: 801-7.

28 Gan TJ, Bennett-Guerrero E, Phillips-Bute B, et al. Hextend, a physiologically balanced plasma expander for large volume use in major surgery: a randomized phase III clinical trial. Hextend Study Group. Anesth Analg 1999; 88: 992-8.

29 Haynes GR, Bailey MK. Excessive use of hetastarch: an iatrogenic cause of bleeding and hypocalcemia? Anesth Analg 2000; 90: 1455-6.

30 American College of Surgeons. Advanced Trauma Life Support Course Manual. Chicago, Illinois: American College of Surgeons; 1997: 103-12.

31 Yoshibara H, Yamamoto T, Mibara $H$. Changes in coagulation and fibrinolysis occurring in dogs during hypothermia. Thromb Res 1985; 37: 503-12.

32 Rohrer MJ, Natale AM. Effect of hypothermia on the coagulation cascade. Crit Care Med 1992; 20: 14025.

33 Reed RL 2nd, Johnston TD, Hudson JD, Fischer RP. The disparity between hypothermic coagulopathy and clotting studies. J Trauma 1992; 33: 465-70.

34 Pina-Cabral JM, Ribeiro-da-Silva A, Almeida-Dias $A$. Platelet sequestration during hypothermia in dogs treated with sulphinpyrazone and ticlopidine - reversibility accelerated after intra-abdominal rewarming. Thromb Haemost 1985; 54: 838-41.

35 Oung CM, Li MS, Shum-Tim D, Chiu RC, Hinchey $E J$. In vivo study of bleeding time and arterial hemorrhage in hypothermic versus normothermic animals. J Trauma 1993; 35: 251-4.

36 Valeri CR, Feingold H, Cassidy G, Ragno G, Khuri S, Altschule MD. Hypothermia-induced reversible platelet dysfunction. Ann Surg 1987; 205: 175-81.

37 Valeri CR, Khabbaz K, Khuri SF, et al. Effect of skin temperature on platelet function in patients undergoing extracorporeal bypass. J Thorac Cardiovasc Surg 1992; 104: 108-16.

38 Michelson AD, MacGregor H, Barnard MR, Kestin AS, Robrer MJ, Valeri CR. Reversible inhibition of human platelet activation by hypothermia in vivo and in vitro. Thromb Haemost 1994; 71: 633-40.

39 Schmied H, Kurz A, Sessler DI, Kozek S, Reiter A. Mild hypothermia increases blood loss and transfusion requirements during total hip arthroplasty. Lancet 1996; 347: 289-92.

40 Douning LK, Ramsay MA, Swygert TH, et al. 
Temperature corrected thrombelastography in hypothermic patients. Anesth Analg 1995; 81: 608-11.

41 Cosgriff N, Moore EE, Sauaia A, Kenny-Moynihan $M$, Burch JM, Galloway B. Predicting life-threatening coagulopathy in the massively transfused trauma patient: hypothermia and acidoses revisited. J Trauma 1997; 42: 857-61; discussion 861-2.

42 Ferrara A, MacArthur JD, Wright HK, Modlin IM, McMillen MA. Hypothermia and acidosis worsen coagulopathy in the patient requiring massive transfusion. Am J Surg 1990; 160: 515-8.

43 Valles J, Santos MT, Aznar J, et al. Erythrocytes metabolically enhance collagen-induced platelet responsiveness via increased thromboxane production, adenosine diphosphate release, and recruitment. Blood 1991; 78: 154-62.

44 Santos MT, Valles J, Marcus AJ, et al. Enhancement of platelet reactivity and modulation of eicosanoid production by intact erythrocytes. A new approach to platelet activation and recruitment. J Clin Invest 1991; 87: 571-80.

45 Valles J, Santos MT, Aznar J, et al. Platelet-erythrocyte interactions enhance alpha(IIb)beta(3) integrin receptor activation and $\mathrm{P}$-selectin expression during platelet recruitment: down-regulation by aspirin ex vivo. Blood 2002; 99: 3978-84.

46 Ouaknine-Orlando B, Samama CM, Riou B, et al. Role of the hematocrit in a rabbit model of arterial thrombosis and bleeding. Anesthesiology 1999; 90: 1454-61.

47 Peyrou V, Lormean JC, Herault JP, Gaich C, Pfliegger $A M$, Herbert JM. Contribution of erythrocytes to thrombin generation in whole blood. Thromb Haemost 1999; 81: 400-6.

48 Valles J, Santos MT, Aznar J, Velert M, Barbera G, Carmena $R$. Modulatory effect of erythrocytes on the platelet reactivity to collagen in IDDM patients. Diabetes 1997; 46: 1047-53.

49 Valles J, Santos MT, Aznar J, et al. Erythrocyte promotion of platelet reactivity decreases the effectiveness of aspirin as an antithrombotic therapeutic modality: the effect of low-dose aspirin is less than optimal in patients with vascular disease due to prothrombotic effects of erythrocytes on platelet reactivity. Circulation 1998; 97: 350-5.

50 Santos MT, Valles J, Aznar J, Marcus AJ, Broekman MJ, Safier LB. Prothrombotic effects of erythrocytes on platelet reactivity. Reduction by aspirin. Circulation 1997; 95: 63-8.

51 Eberst ME, Berkowitz LR. Hemostasis in renal disease: pathophysiology and management. Am J Med 1994; 96: 168-79.

52 Tangelder GJ, Teirlinck HC, Slaaf DW, Reneman RS.
Distribution of blood platelets flowing in arterioles. Am J Physiol 1985; 248(3 Pt 2): H318-23.

53 Teirlinck HC, Tangelder GJ, Slaaf DW, Muijtjens AM, Arts T, Reneman RS. Orientation and diameter distribution of rabbit blood platelets flowing in small arterioles. Biorheology 1984; 21: 317-31.

54 Uijttewaal WS, Nijhof EJ, Bronkhorst PJ, Den Hartog E, Heethaar RM. Near-wall excess of platelets induced by lateral migration of erythrocytes in flowing blood. Am J Physiol 1993; 264(4 Pt 2): H123944.

55 Blajchman MA, Bordin JO, Bardossy L, Heddle NM. The contribution of the haematocrit to thrombocytopenic bleeding in experimental animals. $\mathrm{Br} \mathrm{J}$ Haematol 1994; 86: 347-50.

56 Escolar G, Garrido M, Mazzara R, Castillo R, $\operatorname{Ordinas} A$. Experimental basis for the use of red cell transfusion in the management of anemic-thrombocytopenic patients. Transfusion 1988; 28: 406-11.

57 Livio M, Benigni A, Remuzzi G. Coagulation abnormalities in uremia. Semin Nephrol 1985; 5: 82-90.

58 Small M, Lowe GD, Cameron E, Forbes CD. Contribution of the haematocrit to the bleeding time. Haemostasis 1983; 13: 379-84.

$59 \mathrm{Ho} \mathrm{CH}$. The hemostatic effect of packed red cell transfusion in patients with anemia. Transfusion 1998; 38: 1011-4.

60 Valeri CR, Cassidy G, Pivacek LE, et al. Anemiainduced increase in the bleeding time: implications for treatment of nonsurgical blood loss. Transfusion 2001; 41: 977-83.

61 Khuri SF, Wolfe JA, Josa M, et al. Hematologic changes during and after cardiopulmonary bypass and their relationship to the bleeding time and nonsurgical blood loss. J Thorac Cardiovasc Surg 1992; 104 : 94-107.

62 McLoughlin TM Jr, Fontana JL, Alving B, Mongan $P D$, Bunger R. Profound normovolemic hemodilution: hemostatic effects in patients and in a porcine model. Anesth Analg 1996; 83: 459-65.

63 Friesen RH, Campbell DN, Clarke DR, Tornabene $M A$. Modified ultrafiltration attenuates dilutional coagulopathy in pediatric open heart operations. Ann Thorac Surg 1997; 64: 1787-9.

64 Naik SK, Knight A, Elliott M. A prospective randomized study of a modified technique of ultrafiltration during pediatric open-heart surgery. Circulation 1991; 84(5 Suppl): III422-31.

65 Hiippala ST, Myllyla GJ, Vahtera EM. Hemostatic factors and replacement of major blood loss with plasma-poor red cell concentrates. Anesth Analg 1995; 81: 360-5.

66 Ciavarella D, Reed RL, Counts RB, et al. Clotting 
factor levels and the risk of diffuse microvascular bleeding in the massively transfused patient. $\mathrm{Br} \mathrm{J}$ Haematol 1987; 67: 365-8.

67 Triplett $D A$. Coagulation and bleeding disorders: review and update. Clin Chem 2000; 46(8 Pt 2): 1260-9.

68 Fitzgerald DJ. Vascular biology of thrombosis: the role of platelet-vessel wall adhesion. Neurology 2001; 57(5 Suppl 2): S1-4.

69 Fuss C, Palmaz JC, Sprague EA. Fibrinogen: structure, function, and surface interactions. J Vasc Interv Radiol 2001; 12: 677-82.

70 Nurden AT, Nurden P. A review of the role of platelet membrane glycoproteins in the platelet-vessel wall interaction. Baillieres Clin Haematol 1993; 6: 653-90.

71 Calvete JJ. On the structure and function of platelet integrin alpha IIb beta 3, the fibrinogen receptor. Proc Soc Exp Biol Med 1995; 208: 346-60.

72 Hirshberg A, Dugas M, Banez EI, Scott BG, Wall MJ $J r$, Mattox KL. Minimizing dilutional coagulopathy in exsanguinating hemorrhage: a computer simulation. J Trauma 2003; 54: 454-63.

73 Murray DJ, Olson J, Strauss R, Tinker JH. Coagulation changes during packed red cell replacement of major blood loss. Anesthesiology 1988; 69: 839-45.

74 Harke H, Rahman S. Haemostatic disorders in massive transfusion. Bibl Haematol 1980; 46: 179-88.

75 Harvey MP, Greenfield TP, Sugrue ME, Rosenfeld D. Massive blood transfusion in a tertiary referral hospital. Clinical outcomes and haemostatic complications. Med J Aust 1995; 163: 356-9.

76 Hulka F, Mullins RJ, Frank EH. Blunt brain injury activates the coagulation process. Arch Surg 1996; 131: 923-7; discussion 927-8.

77 Mannucci PM, Federici AB, Sirchia G. Hemostasis testing during massive blood replacement. A study of 172 cases. Vox Sang 1982; 42: 113-23.

78 Harrigan C, Lucas CE, Ledgerwood AM, Mammen $E F$. Primary hemostasis after massive transfusion for injury. Am Surg 1982; 48: 393-6.

79 Harrigan C, Lucas CE, Ledgerwood AM, Walz DA, Mammen EF. Serial changes in primary hemostasis after massive transfusion. Surgery 1985; 98: 836-44.

80 Rodgers RP, Levin J. A critical reappraisal of the bleeding time. Semin Thromb Hemost 1990; 16: 1-20.

81 Samama CM, Quezada R, Riou B, et al. Intraoperative measurement of activated partial thromboplastin time and prothrombin time with a new compact monitor. Acta Anaesthesiol Scand 1994; 38: 232-7.

82 Turi DC, Peerschke EI. Sensitivity of three activated partial thromboplastin time reagents to coagulation factor deficiencies. Am J Clin Pathol 1986; 85: 43-9.

83 Lucas CE, Ledgerwood AM. Clinical significance of altered coagulation tests after massive transfusion for trauma. Am Surg 1981; 47: 125-30.

84 Hewson JR, Neame PB, Kumar N, et al. Coagulopathy related to dilution and hypotension during massive transfusion. Crit Care Med 1985; 13: 387-91.

85 Tuman KJ, Spiess BD, McCarthy RJ, Ivankovich AD. Effects of progressive blood loss on coagulation as measured by thrombelastography. Anesth Analg 1987; 66: 856-63.

86 Cammerer U, Dietrich W, Rampf T, Braun SL, Richter $J A$. The predictive value of modified computerized thromboelastography and platelet function analysis for postoperative blood loss in routine cardiac surgery. Anesth Analg 2003; 96: 51-7.

87 Forestier F, Coiffic A, Mouton C, Ekouevi D, Chene $G$, Janvier $G$. Platelet function point-of-care tests in post-bypass cardiac surgery: are they relevant? $\mathrm{Br} \mathrm{J}$ Anaesth 2002; 89: 715-21.

88 Lasne D, Fiemeyer A, Chatellier G, Chammas C, Baron JF, Aiach M. A study of platelet functions with a new analyzer using high shear stress (PFA 100) in patients undergoing coronary artery bypass graft. Thromb Haemost 2000; 84: 794-9.

89 Kleinman S, Chan P, Robillard P. Risks associated with transfusion of cellular blood components in Canada. Transfus Med Rev 2003; 17: 120-62.

90 Blumberg N, Laczin J, McMican A, Heal J, Arvan $D$. A critical survey of fresh-frozen plasma use. Transfusion 1986; 26: 511-3.

91 Anonymous. Guideline for the use of fresh-frozen plasma. Medical Directors Advisory Committee, National Blood Transfusion Council. S Afr Med J 1998; 88: 1344-7.

92 Hellstern P, Haubelt $H$. Indications for plasma in massive transfusion. Thromb Res 2002; 107(Suppl 1): S19-22.

93 Horsey PJ. Multiple trauma and massive transfusion (Editorial). Anaesthesia 1997; 52: 1027-9.

94 Erber WN. Massive blood transfusion in the elective surgical setting. Transfus Apheresis Sci 2002; 27 : 83-92.

95 Pantanowitz L, Kruskall MS, Uhl L. Cryoprecipitate. Patterns of use. Am J Clin Pathol 2003; 119: 874-81.

96 Cinat ME, Wallace WC, Nastanski F, et al. Improved survival following massive transfusion in patients who have undergone trauma. Arch Surg 1999; 134: 964-8; discussion 968-70.

97 Rivers E, Nguyen B, Havstad S, et al. Early goaldirected therapy in the treatment of severe sepsis and 
septic shock. N Engl J Med 2001; 345: 1368-77.

98 Al Douri M, Shafi T, Al Khudairi D, et al. Effect of the administration of recombinant activated factor VII (rFVIIa; NovoSeven) in the management of severe uncontrolled bleeding in patients undergoing heart valve replacement surgery. Blood Coagul Fibrinolysis 2000; 11(Suppl 1): S121-7.

99 Hendriks $H G$, van der Maaten JM, de Wolf J, Waterbolk TW, Slooff MJ, van der Meer J. An effective treatment of severe intractable bleeding after valve repair by one single dose of activated recombinant factor VII. Anesth Analg 2001; 93: 287-9.

100 Jeffers L, Chalasani N, Balart L, Pyrsopoulos N, Erhardtsen E. Safety and efficacy of recombinant factor VIIa in patients with liver disease undergoing laparoscopic liver biopsy. Gastroenterology 2002; 123: 118-26.

101 Arkin S, Blei F, Fetten J, et al. Human coagulation factor FVIIa (recombinant) in the management of limb-threatening bleeds unresponsive to alternative therapies: results from the NovoSeven emergency-use programme in patients with severe haemophilia or with acquired inhibitors. Blood Coagul Fibrinolysis 2000; 11: 255-9.

102 Poon $M C$, d'Oiron $R$. Recombinant activated factor VII (NovoSeven) treatment of platelet-related bleeding disorders. International Registry on Recombinant Factor VIIa and Congenital Platelet Disorders Group. Blood Coagul Fibrinolysis 2000; 11 (Suppl 1): S5568.

103 Martinowitz U, Holcomb JB, Pusateri AE, et al. Intravenous rFVIIa administered for hemorrhage control in hypothermic coagulopathic swine with grade V liver injuries. J Trauma 2001; 50: 721-9.

104 Martinowitz U, Kenet G, Segal E, et al. Recombinant activated factor VII for adjunctive hemorrhage control in trauma. J Trauma 2001; 51: 431-8; discussion 438-9.

105 Tobias JD. Synthetic factor VIIa to treat dilutional coagulopathy during posterior spinal fusion in two children. Anesthesiology 2002; 96: 1522-5.

106 Martinowitz U, Kenet G, Lubetski A, Luboshitz J, Segal E. Possible role of recombinant activated factor VII (rFVIIa) in the control of hemorrhage associated with massive trauma. Can J Anesth 2002; 49: S15-20.

107 Hedner U. NovoSeven as a universal haemostatic agent. Blood Coagul Fibrinolysis 2000; 11(Suppl 1): S107-11.

108 Allen GA, Hoffman M, Roberts HR, Monroe DM 3rd. Recombinant activated factor VII: its mechanism of action and role in the control of hemorrhage. Can J Anesth 2002; 49: S7-14.
109 Roberts HR. Clinical experience with activated factor VII: focus on safety aspects. Blood Coagul Fibrinolysis 1998; 9 (Suppl 1): S115-8.

110 Hardy JF. Managing uncontrolled hemorrhage in trauma and surgery: a novel and promising approach. Can J Anesth 2002; 49: S4-6.

111 Murkin JM. A novel hemostatic agent: the potential role of recombinant activated factor VII (rFVIIa) in anesthetic practice. Can J Anesth 2002; 49: S21-6.

112 Koh MB, Hunt BJ. The management of perioperative bleeding. Blood Rev 2003; 17: 179-85.

\section{Addendum}

Our review article on the management of massive transfusion and the associated disorders of hemostasis, was first published in the Canadian Journal of Anesthesia in April 2004 (Can J Anesth 2004; 51: 293-310). Written by members of the Groupe d'Intérêt en Hémostase Périopératoire, we felt the article would be an appropriate contribution to the Group's Supplement on "The management of bleeding and thrombosis in the perioperative period: the anesthesiologist's perspective". However, given the relatively short time period elapsed since the initial appearance of the review, we also felt that a revised publication would have been redundant at this time, little new original information having been published in the interim.

Nevertheless, one important article on the use of recombinant activated factor VII (rFVIIa) has been published recently and warrants additional comment. The article by Boffard et al. reports the results of two parallel randomized, placebo-controlled, doubleblind clinical trials on the use of rFVIIa as adjunctive therapy to control bleeding in severely injured trauma patients. ${ }^{l}$

Patients received either rFVIIa (three doses for a total of $400 \mu \mathrm{g} \cdot \mathrm{kg}^{-1}$ ) or an equal volume of placebo and were stratified to blunt or penetrating injury, hence the two trials. The primary endpoint was the total number of red blood cell (RBC) units transfused from start of treatment to $48 \mathrm{hr}$. Secondary endpoints included requirement for other transfusion products (fresh frozen plasma, platelets and cryoprecipitates); mortality; days on the ventilator and days in the intensive care unit. Safety outcomes included frequency and timing of adverse events, and changes in coagulation laboratory variables. In addition, the authors studied a composite endpoint of death and critical complications [multiple organ failure (MOF) and acute respiratory distress syndrome (ARDS)]. 